\title{
Türkiye’de Karpuz Üretiminde Üretim-Fiyat İlişkisinin Almon Gecikme Modeli ile İncelenmesi
}

\author{
Nusret ÖZBAY ${ }^{*}$, Şenol ÇELİK ${ }^{2}$ \\ ${ }^{1}$ Bingöl Üniversitesi Ziraat Fakültesi Bahçe Bitkileri Bölümü, Bingöl \\ ${ }^{2}$ Bingöl Üniversitesi Ziraat Fakültesi Zootekni Bölümü, Bingöl
}

Geliş (Received): 09.03.2015

Kabul (Accepted): 31.03.2016

\begin{abstract}
ÖZET: Bu çalışmada, 1994-2013 yılları arasında karpuzun üretim ve fiyat ilişkisi gecikmesi dağıtılıış modellerden Almon yaklaşımı ile analiz edilmiştir. Modeli belirlemek için karpuz üretim miktarı bağımlı değişken, fiyat değeri ve fiyatların gecikmeli değerleri bağımsız değişkenler olarak tanımlanmıştır. Almon modeli sonuçlarına göre; karpuz üretimi geriye doğru en fazla sekiz yılın fiyatından etkilenmiştir. Diğer yandan, cari yıldaki karpuz fiyatlarındaki 1 TL'lik artış, karpuz üretimini 0.181 ton azaltırken, bir önceki dönemde fiyatlardaki 1 TL'lik artış üretimi 0.107 ton ve sekiz dönem önceki fiyatlardaki 1 TL'lik artış 1.690 ton arttırmıştır. Dolayısıyla karpuz fiyatlarının cari yıldaki değişmelerin üretim üzerinde negatif etki yaptığı, ancak birinci dönemden sekizinci döneme kadar olan gecikmeli değerlerindeki değişmelerin üretim üzerinde pozitif etki yaptı̆̆ı ortaya çıkmıştır.
\end{abstract}

Anahtar Kelimeler: Karpuz üretimi, fiyat, gecikmesi dağıtılmış model, Almon modeli

\section{Investigation by Almon Lag Model of Production and Price Relationships in Watermelon Production in Turkey}

\begin{abstract}
In this study, watermelons production and price relationship between the years 1994-2013 were analyzed by Almon approach, one of the distributed lag models. To determine the model, the amount of watermelon production was defined as dependent variable, and watermelon price series and the distributed lag values of the prices were determined as independent variables. According to Almon model; watermelon production is mostly influenced by the price back up to eight years. On the other hand, while increase of one Turkish lira in the price of watermelons in current year decreased watermelon production by 0.181 ton. Increase of one Turkish lira in the price of watermelons in the previous year, and eight years back increased watermelon production by 0.107 and 1.69 tons, respectively. Therefore, it has been determined that changes in the delayed values of watermelons prices in the current year, had a negative impact on production, but changes in the delayed values of watermelons prices from the first to the eight periods. It could be concluded that this situation had a positive effect on watermelon production.

Key Words: Watermelon production, price, distributed lag model, Almon model
\end{abstract}

\section{GÍRIŞ}

Karpuz (Citrullus lanatus) tek yıllık bir kültür bitkisi olup, dünyada en fazla üretilen ve tüketilen sebze türlerinden birisidir. Dünyada toplam 3472977 ha alanda 109278714 ton karpuz üretilmektedir (FAO, 2013). Dünya karpuz üretiminde Türkiye 4 milyon ton üretim değeri ile Çin'den sonra 2. sırada yer almaktadır. Ülkemizde karpuz, üretim, tüketim ve ekonomideki değeri bakımından sebzeler içerisinde ikinci sırada yer almaktadır.

Yetiştiriciliği yapılan bölgelerde karpuz üreticilerinin önemli gelir kaynaklarından birisini oluşturmaktadır. Ancak karpuz üretimi doğa koşullarından oldukça fazla etkilenmektedir. $\mathrm{Bu}$ durumun doğal sonucu olarak üreticiler, birçok üründe olduğu gibi karpuz üretim sürecinde de risk ve belirsizliklerle karşı karşıya kalmaktadırlar. Bunun yanında karpuz üretimin daha çok küçük ölçekli işletmeler tarafından yapılması nedeniyle üreticilerin bir araya gelerek üretim miktarını belirlemeleri, fiyatları kendi lehlerine çevirmeleri ve bir sonraki yıl için üretim planı yapmaları çoğu zaman mümkün olmamaktadır
$\mathrm{Bu}$ durum tarımsal ürün piyasalarında üretim miktarı ve fiyatlarda dalgalanmaların ortaya çıkmasına neden olmaktadır (Özgüven,1983).

Özellikle üretimi zamana bağlı olan tarımsal mallarda arzın, talep değişmelerine cevap verebilmesi için belli bir süre geçmesi gerekmektedir. Böyle bir durumda, arz geçmişte verilen bir kararın sonucu olarak şekillenmekte ve arz edilen miktar da bir önceki dönem fiyatının bir fonksiyonu olmaktadır (Gürler, 2012). Dolayısıyla üreticiler bulundukları dönemin üretim kararlarını bir önceki dönemin ürün fiyatlarından etkilenerek almaktadırlar. Tarımsal ürünlerde bu yapısal özellik nedeniyle, üretim miktarı-fiyat ilişsisi Gecikmesi Dağıtılmış Modeller yardımıyla incelenebilmektedir (Erdal, 2006). Bu modellerden bir tanesi de Almon modelidir. Almon modeli, bilinmeyen parametrelerinin zamanla ikinci veya üçüncü derece eğrisi şeklinde değiştiğini varsayarak dağıtılmış gecikme modellerini tahmin eden bir modeldir.

Türkiye'de gecikmesi dağıtılmış modeller kullanılarak tarımsal ürün fiyat ilişkisini inceleyen çalışmalar bulunmaktadır. Yurdakul (1998) tarafından

*Sorumlu yazar: Özbay, N., oznusret@ yahoo.com 
yapılan çalışmada, 1985-1997 yılları arasında pamuk üretimi ile pamuk fiyatları arasındaki ilişki Koyck ve Almon modeli ile incelenmiştir. Dikmen (2006) tarafından yapılan çalışmada 1982-2003 döneminde tütün üretimi ile fiyatı arasındaki ilişki; Erdal ve Erdal (2008), 1975-2006 dönemine ait kuru soğanda üretim fiyat etkileşimi, Erdal ve ark. (2009)'nın çalışmalarında 1975-2006 döneminde patates üretimi ve fiyatı arasındaki ilişki, Çetinkaya (2012) tarafından yapılan çalışmada, 2002-2011 döneminde buğday üretimi ile buğday fiyatları arasındaki ilişki; Doğan ve Gürler (2013) tarafından yapılan çalışmada kuru soğan üretim ve fiyat ilişkisi; Doğan ve ark. (2014) tarafından yürütülen ve 1993-2013 yıllarını kapsayan bir çalışmada Samsun ili çeltik üretim-fiyat ilişkisinin incelenmesinde Almon modeli kullanılmıştır. Daha önce yürütülen bir çalışmada Türkiye karpuz üretiminde, üretim miktarı ve fiyat ilişkisi gecikmesi dağıtılmış modellerden Koyck modeli ile incelenmiştir (Abdikoğlu ve Unakıtan, 2014).

Bu çalışmada, Türkiye'de karpuz üretimi ve fiyatları arasındaki ilişkisinin bir gecikmesi dağıtılmış model olan Almon modeli ile açıklanması amaçlanmıştır. Bildiğimiz kadarıla daha önce ülkemizde karpuzda Almon modeli kullanılmamıştır.

\section{MATERYAL VE METOT}

Materyal

Karpuz üretimi ve fiyat ilişkisini ortaya koymak için Gecikmesi Dağıtılmış Almon Modeli kullanılmıştır. Karpuz üretim miktarı bağımlı değişken, karpuz fiyatı ise bağımsız değişken olarak ele alınmıştır. Karpuz fiyatı, çiftçinin eline geçen ortalama taban fiyattır. Karpuz üretim miktarı ise ton cinsindendir. Değişkenlere ait veriler yıllıktır ve 1994-2013 yılları arasını kapsamaktadır. Üretim miktarı verileri TÜIKK (2012), TÜİK (2013), fiyat verileri ise FAO (2013) kayıtlarından sağlanmıştır.

\section{Metot}

Gecikmesi dağıtılmış modeller, bağımsız değişkenin sadece bugünkü değerini değil, geçmiş yıllardaki değerlerini de kapsamaktadır (İşyar, 1999). Almon modeli gecikmesi dağıtılmış diğer modeldir. Almon modelinde $\beta$ parametreleri önce artıp sonra azalabilir veya önce azalıp sonra artabilir (Cezayirli, 2007).

Almon (1965) tarafindan bu olasılıkları kapsayacak şekilde ve Weierstrass Teoremi yardımıyla, model geliştirmiştir. Modelde $\beta$ değerleri i’nin (gecikmenin) belli bir derecedeki fonksiyonu olarak ifade edilmektedir.

Genel olarak

$$
\mathrm{Y}_{\mathrm{t}}=\alpha_{0}+\beta_{0} \mathrm{X}_{\mathrm{t}}+\beta_{1} \mathrm{X}_{\mathrm{t}-1}+\beta_{2} \mathrm{X}_{\mathrm{t}-2}+\ldots+\beta_{\mathrm{k}} \mathrm{X}_{\mathrm{t}-\mathrm{k}}+\varepsilon_{\mathrm{t}}
$$

şeklinde ifade edilen sonlu gecikmesi dağıtılmış model

$$
\mathrm{Y}_{\mathrm{t}}=\alpha_{0}+\sum_{\mathrm{i}=0}^{\mathrm{k}} \beta_{\mathrm{i}} \mathrm{X}_{\mathrm{t}-\mathrm{i}}+\varepsilon_{\mathrm{t}}
$$

olarak yazılabilir (Amemiya, 1985).

Çok terimli gecikme modeli,

$$
\beta_{i}=a_{0}+a_{1}^{i}+a_{2}^{i^{2}}+\ldots+a_{m}^{i^{m}}
$$

biçiminde bir polinomdur.

Almon modelinin ikinci derecede bir polinom olduğu durumu ele alındığında, Eşitlik (3), Eşitlik (2)'de yerine konursa

$$
Y_{t}=\alpha_{0}+a_{0} \sum_{i=0}^{k} X_{t-i}+a_{1} \sum_{i=0}^{k} \mathrm{iX}_{t-i}+a_{2} \sum_{i=0}^{k} i^{2} X_{t-i}+\varepsilon_{t}
$$

veya

$$
Y_{t}=\alpha_{0}+\sum_{i=0}^{k}\left(a_{0}+a_{1}^{i}+a_{2}^{i^{2}}\right) X_{t-i}+\varepsilon_{t}
$$

elde edilir. Burada $Z_{0 t}=\sum_{i=0}^{k} X_{t-i}, Z_{1 t}=\sum_{i=0}^{k} i X_{t-i}$ ve $\mathrm{Z}_{2 \mathrm{t}}=\sum_{\mathrm{i}=0}^{\mathrm{k}} \mathrm{i}^{2} \mathrm{X}_{\mathrm{t}-\mathrm{i}}$ kısaltmaları yapılarak

$$
Y_{t}=\alpha_{0}+a_{0} Z_{0 t}+a_{1} Z_{1 t}+a_{2} Z_{2 t}+\varepsilon_{t}
$$

biçimindeki denkleme ulaşılır. Almon modelinin uygulanması için gecikme uzunluğunun (k) ve çokterimlinin derecesinin $(\mathrm{m})$ tespit edilmesi gerekir (Gujarati, 2001). Kisaca polinom derecesi $\mathrm{m}=2$ ve gecikme sayısı k=8 olduğunda Z'ler (7), (8) ve (9) nolu eşitliklerde olduğu gibidir.

$\mathrm{Z}_{0 \mathrm{t}}=\sum_{\mathrm{i}=0}^{8} \mathrm{X}_{\mathrm{t}-\mathrm{i}}=\mathrm{X}_{\mathrm{t}}+\mathrm{X}_{\mathrm{t}-1}+\mathrm{X}_{\mathrm{t}-2}+\mathrm{X}_{\mathrm{t}-3}+\mathrm{X}_{\mathrm{t}-4}+\mathrm{X}_{\mathrm{t}-5}+\mathrm{X}_{\mathrm{t}-6}+\mathrm{X}_{\mathrm{t}-7}+\mathrm{X}_{\mathrm{t}-8}$

$\mathrm{Z}_{1 \mathrm{t}}=\sum_{\mathrm{i}=0}^{8} \mathrm{i} \mathrm{X}_{\mathrm{t}-\mathrm{i}}=\mathrm{X}_{\mathrm{t}-1}+2 \mathrm{X}_{\mathrm{t}-2}+3 \mathrm{X}_{\mathrm{t}-\mathrm{3}}+4 \mathrm{X}_{\mathrm{t}-\mathrm{4}}+5 \mathrm{X}_{\mathrm{t}-5}+6 \mathrm{X}_{\mathrm{t}-6}+7 \mathrm{X}_{\mathrm{t}-\mathrm{7}}+8 \mathrm{X}_{\mathrm{t}-8}$

$\mathrm{Z}_{2 \mathrm{t}}=\sum_{\mathrm{i}=0}^{8} \mathrm{i}^{2} \mathrm{X}_{\mathrm{t}-\mathrm{i}}=\mathrm{X}_{\mathrm{t}-1}+4 \mathrm{X}_{\mathrm{t}-2}+9 \mathrm{X}_{\mathrm{t}-3}+16 \mathrm{X}_{\mathrm{t}-4}+25 \mathrm{X}_{\mathrm{t}-5}+36 \mathrm{X}_{\mathrm{t}-6}+49 \mathrm{X}_{\mathrm{t}-7}+64 \mathrm{X}_{\mathrm{t}-8}$

(9)

oluşturulan bu modellerden ana modele dönüşüm yapıldığında Eşitlik (6)'da verilen denklem elde edilir.

Eşitlik (6)'ya dönüşümden sonra, ikinci dereceden çok terimli gecikme şemasında, gecikme sayısı kadar tam sayı verilir ve EKK yöntemi ile model tahmin edildiğinde; $a_{0}, a_{1}$ ve $a_{2}$ katsayıları bulunur. Bulunan "a" katsayıları yerlerine konulduğunda ise " $\beta$ " katsayılarına ulaşılır (Tarı, 2005). $\beta$ katsayılarının "a" cinsinden değerleri Eşitlik (10)-(18)'de olduğu gibi bulunur.

$$
\mathrm{i}=0 \quad \beta_{0}=\mathrm{a}_{0}
$$




$$
\begin{array}{ll}
i=1 & \beta_{1}=a_{0}+a_{1}+a_{2} \\
i=2 & \beta_{2}=a_{0}+2 a_{1}+4 a_{2} \\
i=3 & \beta_{3}=a_{0}+3 a_{1}+9 a_{2} \\
i=4 & \beta_{4}=a_{0}+4 a_{1}+16 a_{2} \\
i=5 & \beta_{5}=a_{0}+5 a_{1}+25 a_{2} \\
i=6 & \beta_{6}=a_{0}+6 a_{1}+36 a_{2} \\
i=7 & \beta_{7}=a_{0}+7 a_{1}+49 a_{2} \\
i=8 & \beta_{8}=a_{0}+8 a_{1}+64 a_{2}
\end{array}
$$

Polinom derecesi, her bükülme (maksimum veya minimum noktaları) sayısından en az bir fazladır. Bükülme noktaları önceden bilinemez, k'nın ve i'nin belirlenmesi büyük ölçüde özneldir. Bu yüzden k'nın ve m’nin belirlenmesi araştırmacının öngörüsüne kalmıştır (Akın, 2002). Modeldeki uygun gecikme için AIC (Akaike Bilgi Kriteri) ve SBC (Schwarz Bayesian Kriteri) kullanılır. En küçük AIC veya SBC değerini veren model en uygun model olarak seçilir (Kutlar, 2005).

Akaike Bilgi Kriteri (AIC);

$$
\mathrm{AIC}=\mathrm{T} \ln \sigma^{2}+2 \mathrm{n}
$$

SBC (Schwarz Bayesian Kriteri);

$$
\mathrm{SBC}=\mathrm{T} \ln \sigma^{2}+\mathrm{nln}(\mathrm{T})
$$

biçiminde ifade edilir (Cooray, 2008). Burada;

$\mathrm{T}=$ Kullanılabilir gözlem sayısı,

$\mathrm{n}=$ Tahmin edilen parametre sayısı,

$\mathrm{Bu}$ kriterlerin dişında gecikme uzunluğunun belirlenmesine ilişkin farklı yöntemler de vardır. $\mathrm{Bu}$ yöntemler, maksimum gecikme uzunluğu bilindiği zaman gecikme uzunluğunun tahmini (Judge et al., 1988; Thomas, 1997; Genceli, 2001) ve gecikme uzunluğunun çapraz korelasyon fonksiyonu yardımı ile tahminidir (Lardaro, 1993). Gecikmesi dağıtılmış modeller modele özgü tahmini en küçük kareler (EKK) yöntemi ile yapılır (Tinbergen, 1949; Tarı, 2005).

\section{BULGULAR VE TARTIŞMA}

Türkiye'nin karpuz üretimi incelendiğinde, devamlı artış veya azalış gösteren değil, hem artan hem da azalan olmak üzere inişli çıkışlı bir üretim gerçekleşmiştir (Şekil 1). Karpuz taban fiyatları 2004 yılına kadar devamlı bir artış göstermiştir (Şekil 2). 2005 yılından 2013 yılına kadar artışlı azalışlı bir durum göstermiştir. Karpuz fiyatı 2010 yılında en yüksek değere ulaşmıştır.

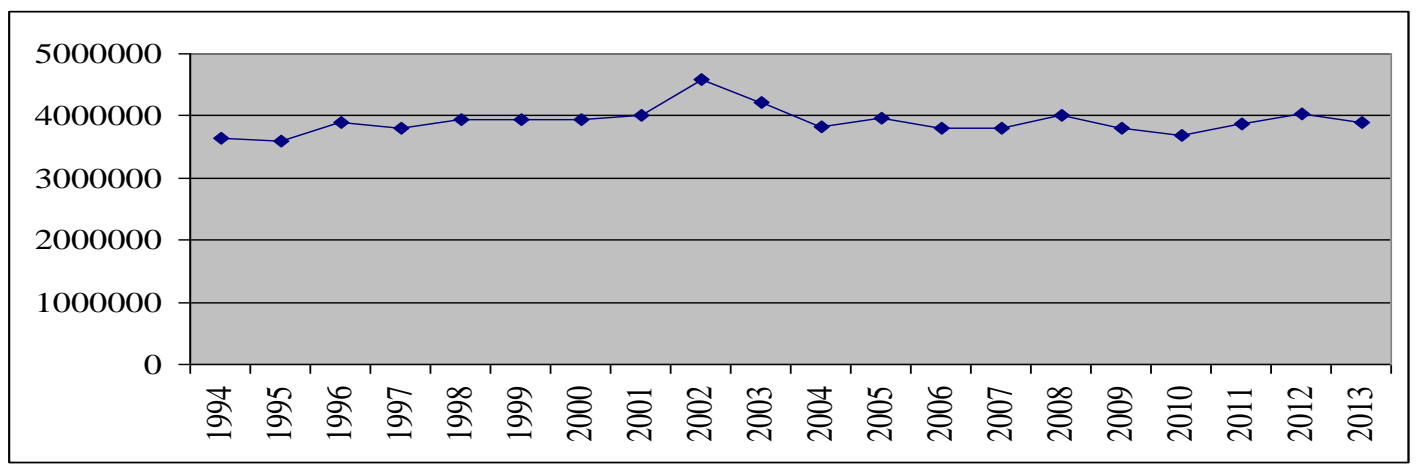

Şekil 1. Türkiye'de yıllara göre karpuz üretimi (ton)

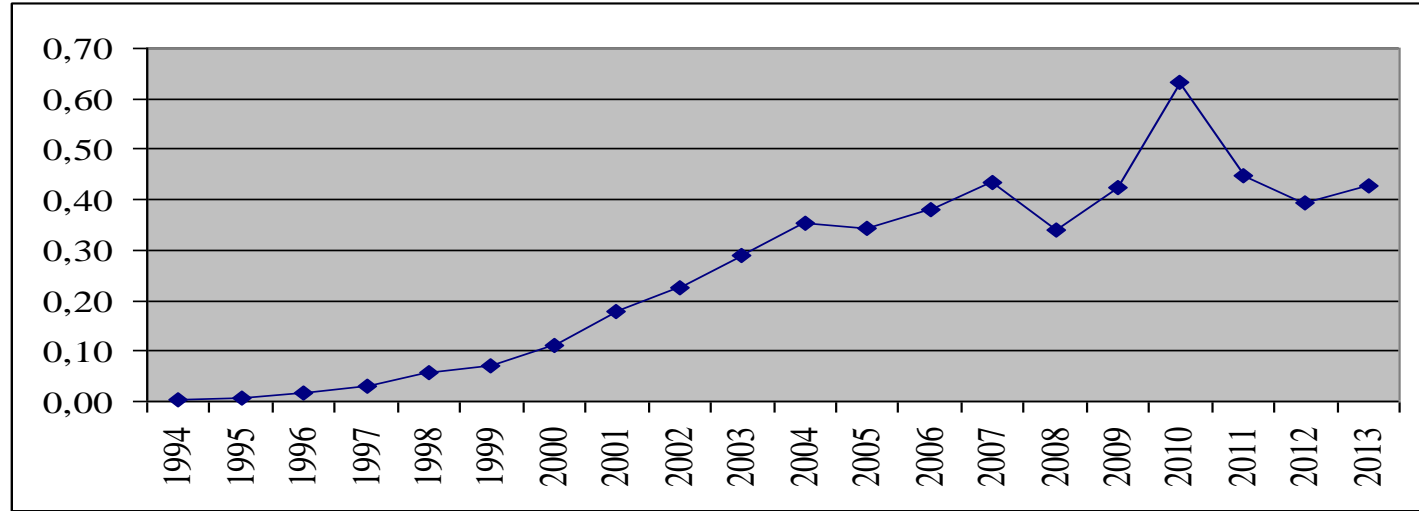

Şekil 2. Türkiye'de yıllara göre karpuz fiyatları 
Karpuz üretim-fiyat ilişkisinin, gecikmesi dağıtılmış modellere uygun olup olmadığını belirlemek için, değişkenler arasındaki ilişkinin korelasyon katsayısı 0.90 olarak hesaplanmıştır ve oldukça yüksek bir değerdir. Almon modelinin oluşturulabilmesi için incelenen verilerden karpuz fiyatının gecikmeli değerinin bilinmesi gerekir. Modelde gecikme uzunluğunun tespiti için AIC kriteri ile birlikte, Schwartz gecikme uzunluğu kriteri (Schwartz, 1978) kullanılmıştır. $\mathrm{Bu}$ nedenle büyük bir $\mathrm{q}$ (gecikme uzunluğu) değeriyle dağıtılmış gecikmenin şekli konusunda hiçbir sınırlama koymadan, bu süre kısaltıldığında modelin önemli bir bozulmaya uğrayıp uğramadığı araştırılır (Davidson ve MacKinnon 1993). Çalışmada, geriye dönük karpuz üretiminin en fazla kaç y1l önceki fiyatlardan etkilendiğinin belirlemek için elde edilen AIC ve SBC değerleri farklı gecikme uzunluklarında Çizelge 1' de sunulmuştur.

Çizelge 1. Farklı Gecikme Uzunluklarında AIC ve SBC Değerleri

\begin{tabular}{lcc}
\hline Gecikme uzunluğu & AIC Değeri & SBC Değeri \\
\hline $\mathrm{k}=2$ & 27.37 & 27.67 \\
$\mathrm{k}=3$ & 27.51 & 27.76 \\
$\mathrm{k}=4$ & 27.55 & 27.84 \\
$\mathrm{k}=5$ & 27.79 & 28.12 \\
$\mathrm{k}=6$ & 27.82 & 28.19 \\
$\mathrm{k}=7$ & 27.70 & 28.09 \\
$\mathrm{k}=8$ & 26.63 & 27.03 \\
\hline
\end{tabular}

Çizelge 1'de görüldüğü gibi, en düşük AIC ve SBC değerlerine karşılık gelen uygun gecikme uzunluğu 8 'dir. Belirlenen gecikme uzunluğuna göre incelenen dönemde karpuz üretimi ile fiyatı arasındaki ilişki en küçük kareler yöntemi (EKK) kullanılarak tahmin edilmiştir ve Çizelge 2'de verilmiştir ve Eşitlik (1)'deki gibi tahmin edilmiştir. Dikmen (2006)'in tütün üretimfiyat ilişkisi 3 gecikme, Doğan ve Gürler (2013)'in çalışmalarında kuru soğan üretim miktarı ile fiyatı arasındaki ilişki 7 gecikme uzunluğuna göre gecikmesi dağıtılmış Almon modeli ile incelenmiştir. Türkiye'de karpuz ile ilgili daha önceden üretim-fiyat ilişkisi çalışması olmadı̆̆ından burada diğer ürünlerle ilgili tespit edilen sonuçlar karşılaştırılmıştır.

Çizelge 2. Karpuz İçin Üretim-Fiyat İlişkisinin Gecikmesi Dağıtılmış Model Sonuçları

$\mathrm{Q}_{\mathrm{t}}=5104689-1.490 \beta_{\mathrm{t}}-1.140 \beta_{\mathrm{t}-1}-0.805 \beta_{\mathrm{t}-2}-0.485 \beta_{\mathrm{t}-3}-0.181 \beta_{\mathrm{t}-4}+0.107 \beta_{\mathrm{t}-5}+0.380 \beta_{\mathrm{t}-6}+0.637 \beta_{\mathrm{t}-7}+0.879 \beta_{\mathrm{t}-8}$

\begin{tabular}{|c|c|c|c|c|c|c|c|c|c|c|}
\hline & \multicolumn{10}{|c|}{ Gecikme dönemleri } \\
\hline & Sabit & $\mathrm{t}$ & $\mathrm{t}-1$ & $\mathrm{t}-2$ & $t-3$ & $t-4$ & $t-5$ & $t-6$ & $\mathrm{t}-7$ & $\mathrm{t}-8$ \\
\hline $\operatorname{Katsay1}(\beta)$ & $5104689 *$ & $-1.49 * *$ & $-1.14 * *$ & $-0.805^{* *}$ & $-0.485^{*}$ & -0.181 & 0.107 & $0.38 * *$ & $0.637 * *$ & 0.879 \\
\hline t-değeri & 23.700 & -3.059 & -4.501 & -4.483 & -2.203 & -0.757 & 0.529 & 2.769 & 2.908 & 1.860 \\
\hline $\mathrm{R}^{2}=0.81$ & $\mathrm{~F}=11.31$ & $\mathrm{p}=0.003$ & $\mathrm{DW}=2.13$ & & & & & & & \\
\hline
\end{tabular}

Çizelge 2'deki model sonuçlarına göre, cari yılda, t-1, t$2, \mathrm{t}-3$ ve $\mathrm{t}-4$ dönemdeki fiyatlar karpuz üretimini negatif yönde etkilerken, t-5, t-6, t-7 ve t-8 dönemdeki fiyatlar karpuz üretimini pozitif yönde etkilemiştir. Modele ait parametreler incelendiğinde $\beta_{0}, \beta_{1}, \beta_{2}, \beta_{3}, \beta_{6}$ ve

$\beta_{7}$ kısmi regresyon katsayıları istatistiksel olarak anlamlı bulunmustur $(\mathrm{P}<0.05$ ve $\mathrm{P}<0.01)$. Kisaca, $\mathrm{t}, \mathrm{t}-1$, $\mathrm{t}-2, \mathrm{t}-3, \mathrm{t}-6$ ve $\mathrm{t}-7$ dönemlerine ait parametrelerin tahmini istatistiksel olarak önemli bulunmuştur. Modelin korelasyon katsayısı ise $\mathrm{r}=0.90$ 'dır ve oldukça yüksek bir korelasyon değerine sahiptir. $\beta_{5}$ ve $\beta_{8}$ katsayıları istatistiksel olarak önemsiz çıksa da, modelin açıklama gücünü ifade eden $\mathrm{R}^{2}=0.81$ olarak elde edilmiştir. Dikmen (2006)'in tütün üretimi-fiyat ilişkisi çalışmasında $\mathrm{R}^{2}=0.87$, Doğan ve Gürler (2013)'in kuru soğan üretim-fiyat ilişkisi araştırmasında $R^{2}=0.85$ bulunmuştur. $\mathrm{Bu}$ modelde $\mathrm{F}=11.31$ bulunmuştur. Model genel olarak anlamlı çıkmıştır $(\mathrm{P}<0.01)$. Durbin-Watson (DW) $d=2.13$ istatistiği değerine göre otokorelasyon sorunu bulunmamaktadır.

Üreticiler 5, 6, 7 ve 8 dönem önceki fiyat düzeyinin etkisinde kalarak üretimi arttırma yolunu tercih etmiştir. Modelde " $Z$ " değerleri elde edilmiştir. Z değerleri için modelin derecesi $\mathrm{m}=2$ olarak kabul edilmiştir ve Eşitlik (6)'da ifade edilen bu denklem Çizelge 3'deki model sonuçlarına göre Eşitlik (19)'da olduğu gibi yazılabilir. 
Çizelge 3. Almon modeli ile karpuz üretimi ve fiyat ilişkisinin tahmini

\begin{tabular}{crrrr}
\hline Değişken & \multicolumn{1}{c}{ Katsay1 } & \multicolumn{1}{c}{ Std. Hata } & t-istatistiği & \multicolumn{1}{c}{$\mathrm{P}$} \\
\hline $\mathrm{C}$ & 5104689 & 215388.4 & 23.700 & 0.000 \\
$Z_{0}$ & -0.181 & 0.240 & -0.757 & 0.471 \\
$Z_{1}$ & 0.296 & 0.067 & 4.440 & 0.002 \\
$Z_{2}$ & -0.007 & 0.040 & -0.196 & 0.8492 \\
\hline
\end{tabular}

$Q_{t}=5104689-0.181 Z_{0}+0.296 Z_{1}-0.007 Z_{2}+\varepsilon_{t}$

Çizelge 3'deki Z değerleri elde edildikten sonra Eşitlik (10)-(18) arasındaki çözümlemeler yapılarak Eşitlik (20)-(28) sonuçları elde edilmiştir.

$\beta_{0}=\mathrm{a}_{0}=-0.181$

$\beta_{1}=a_{0}+a_{1}+a_{2}=-0.181+0.296-0.007=0.107$

$\beta_{2}=a_{0}+2 a_{1}+4 a_{2}=-0.181+2(0.296)+4(-0.007)=0.380$

$\beta_{3}=a_{0}+3 a_{1}+9 a_{2}=-0.181+3(0.296)+9(-0.007)=0.637$

$\beta_{4}=a_{0}+4 a_{1}+16 a_{2}=-0.181+4(0.296)+16(-0.007)=0.879$

$\beta_{5}=\mathrm{a}_{0}+5 \mathrm{a}_{1}+25 \mathrm{a}_{2}=-0.181+5(0.296)+25(-0.007)=1.105$

$\beta_{6}=a_{0}+6 a_{1}+36 a_{2}=-0.181+6(0.296)+36(-0.007)=1.316$

$\beta_{7}=\mathrm{a}_{0}+7 \mathrm{a}_{1}+49 \mathrm{a}_{2}=-0.181+7(0.296)+49(-0.007)=1.511$

$\beta_{8}=a_{0}+8 a_{1}+64 a_{2}=-0.181+8(0.296)+64(-0.007)=1.690$

(28)

Elde edilen bu değerlere göre Almon Modeli Eşitlik (29)'daki gibi yazılabilir.

$\mathrm{Q}_{\mathrm{t}}=5104689-0.181 \mathrm{P}_{\mathrm{t}}+0.107 \mathrm{P}_{\mathrm{t}-1}+0.380 \mathrm{P}_{\mathrm{t}-2}+0.637 \mathrm{P}_{\mathrm{t}-3}$

$+0.879 \mathrm{P}_{\mathrm{t}-4}+1.105 \mathrm{P}_{\mathrm{t}-5}+1.316 \mathrm{P}_{\mathrm{t}-6}+1.511 \mathrm{P}_{\mathrm{t}-7}+1.690 \mathrm{P}_{\mathrm{t}-8}$

Almon modeli sonuçlarına göre, $\mathrm{t}$ dönemindeki fiyatlarda bir birimlik değişim, üretim miktarında 0.181 birim azalışa neden olurken, t-1 dönemdeki fiyatlarda oluşacak bir birimlik artış üretim miktarında 0.107 birimlik artışa neden olmaktadır. Benzer şekilde sirasiyla $\mathrm{t}-2, \mathrm{t}-3, \mathrm{t}-4, \mathrm{t}-5, \mathrm{t}-6, \mathrm{t}-7$ ve $\mathrm{t}-8$ dönemlerindeki fiyatlarda meydana gelecek bir birimlik artış üretim miktarında $0.380,0.637,0.879,1.105,1.316,1.511$ ve 1.690 birimlik artışa neden olmaktadır.

\section{SONUÇ}

$\mathrm{Bu}$ araştırmada, karpuz üretim miktarı ile fiyatlar arasındaki etkileşim "gecikmesi dağıtılmış modellerden Almon modeli” ile açıklanmıştır. 1994-2013 dönemini kapsayan karpuz üretim miktarı bağımlı değişken, fiyatlar ise bağımsız değişken olarak ele alınmıştır.
İncelenen dönemde karpuz üretim miktarı ile fiyatlar arasında $\% \quad 90$ değerinde yüksek bir korelasyon bulunmuştur. $\mathrm{Bu}$ ilişki, karpuz üretim miktarı fiyat ilişkisini açıklamada Almon modeline uygun bir ürün olduğu anlamındadır.

(AIC) ve SBC yardımıyla gecikme uzunluğu belirlenerek model oluşturulmuştur. En küçük AIC ve SBC değerine sahip maksimum gecikme olan 8 değeri karpuzun en fazla 8 yıl önceki fiyatlardan etkilendiği belirlenmiştir. Almon modeli sonuçlarına göre, karpuz üretim miktarının geçmiş 1 yıldaki fiyatlardan negatif olarak etkilendiği, 2.-8. y1llardaki fiyatlardan ise pozitif olarak etkilendiği görülmüştür.

Sonuç olarak, serbest piyasa şartlarında oluşan karpuz fiyatlarının, üretim miktarını belirlemede etkisinin çok yüksek olduğu görülmektedir. Karpuz fiyatları, serbest piyasa şartlarında bir önceki yılın fiyatlarına, üretim miktarına ve diğer faktörlere bağlıdır. Daha öncede belirtildiği gibi dünya karpuz üretiminde Türkiye 2. sırada yer almaktadır. Ülkemizin dünya pazarındaki yeri incelendiğinde karpuz üretim planlaması ve fiyat istikrarı yönünden önem verilmesi gereken bir ürün olmalıdır.

\section{KAYNAKLAR}

Abdikoğlu, D.İ., Unakıtan, G. 2014. Türkiye'de Karpuz Üretimi ile Karpuz Fiyatı Arasındaki İlişkinin Ekonometrik Analizi. XI. Ulusal Tarım Ekonomisi Kongresi, 3-5 Eylül, Samsun. Cilt II: 854-859.

Akın, F. 2002. Ekonometri. Ekin Kitabevi, Bursa, 742 s. Almon, S. 1965. The Distributed Lag Between Capital Appropriations and Expenditures. Econometrica, 33(1): 178-196.

Amemiya, T., 1985. Advanced Econometrics. Harvard University Pres, Cambridge.

Cezayirli, M. A. 2007. Gecikmesi Dağıtılmış Modeller (Türkiye Örneği), Gaziosmanpaşa Üniversitesi, Sosyal Bilimler Enstitüsü Yüksek Lisans Tezi, Tokat.

Cooray, T. M. J. A., 2008. Applied Time Series Analysis of Forecasting. Narosa Publishing House Pvt. Ltd.

Çetinkaya, Ş. 2012. Türkiye'nin Son On Yıllık Buğday Üretimdeki Miktar-Fiyat İlişkisinin Ekonometrik Analizi: Koyck - Almon Tekniği. İnsan ve Toplum Bilimleri Araştırmaları Dergisi, 1(4): 52-66.

Davidson, R., MacKinnon J.G. 1993. Estimation and ference in Econometrics, Oxford University Pres, New York: 675-676.

Dikmen, N. 2006. Koyck-Almon Yaklaşımı İle Tütün Üretimi ve Fiyat İlişkisi. Ç.Ü. Sosyal Bilimler Enstitüsü Dergisi, 15(2): 153-168.

Doğan, H. G., Gürler, Z. 2013. Gecikmesi Dağıtılmış Ekonometrik Modelin Seçilmiş Bir Tarım Ürünü Üzerine Uygulanması (Kuru Soğanda Almon Modeli Örneği). Akademik Bakış Dergisi, 39: 1-12. 
Doğan, H. G., Gürler, A. Z., Ayyıldız, B., Şimşek, E. 2014. Patates Üretiminde Üretim-Fiyat İlişkisinin Koyck Yaklaşımı ile Analitik Olarak Değerlendirilmesi (TR71 Bölgesi Örneği). Türk Tarım-Gıda Bilim ve Teknoloji Dergisi, 2(1): 42-46.

Erdal, G. 2006. Tarımsal Ürünlerde Üretim-Fiyat İlişkisinin Koyck Yaklaşımı ile Analizi (Domates Örneği). Gaziosmanpaşa Üniversitesi, Ziraat Fakültesi Dergisi, 23: 17-24. Erdal, G., Erdal, H. 2008. Kuru Soğanda Üretim Fiyat Etkileşimi. GOPÜ, Ziraat Fak. Derg., 25(1): 33-39.

Erdal, H., Erdal, G., Esengün, K. 2009. An Analysis of Production and Price Relationship for Potato in Turkey: A Distributed Lag Model Application, 15: 243-250 p.

FAO, 2013. Statistical database of food and agriculture organization of the United Nations, http://faostat3.fao.org/download/Q/QC/E (Erişim tarihi: 27.02.2015).

Genceli, M. 2001. Ekonometri ve İstatistik ilkeleri. Filiz Kitabevi, İstanbul, $772 \mathrm{~s}$

Gujarati, D. N. 2001. Temel Ekonometri (Çevirenler: Ümit Şenesen, Gülay Günlük Şenesen). Literatür Yayınlar1 No:33, İstanbul.

Gürler, A. Z. 2012. Analitik Tarım Ekonomisi. Geliştirilmiş 2. Basım, Nobel Yay., Ankara. 214 s.

İşyar, Y. 1999. Ekonometrik Modeller. Uludağ Üniversitesi Güçlendirme Vakfı Yayınları, Yayın No: 141, Bursa.
Judge, G. G., Hill, R. C., Griffiths, W. E., Lütkepohl, H., Lee, T. C. 1988. Introduction to The Theory and Practice of Econometrics. 2 nd edition, John Wiley, New York, 1024 p.

Kutlar, A. 2005. Uygulamal1 Ekonometri. Nobel Yayın No:769, Teknik Yayınlar: 97, İstanbul, 205-207.

Lardaro, L. 1993. Applied Econometrics. Harper Collins, New York.

Özgüven, A., 1983, Tarım Ekonomisi ve Politikası, Filiz Kitabevi, İstanbul, sh. 175-178.

Schwartz, G. 1978. Estimating the Dimension of a Model. The Annals of Statistics, 5(2): 461-464.

Tarı, R. 2005. Ekonometri. Gözden Geçirilmiş ve Genişletilmiş 3. Bask1, Kocaeli Üniversitesi Yayınları, Yayın No:172, Kocaeli.

Thomas, R. L. 1997. Modern Econometrics and Introduction, Addision-Wesley, Cambridge.

Tinbergen, J. 1949. Long-Term Foreign Trade Elasticities. Macroeconomica, c1, 174-185 p.

TÜİK, 2012. İstatistik göstergeler 1923-2012, Türkiye İstatistik Kurumu Matbaas1, Yayın No: 4132, Ankara, $698 \mathrm{~s}$.

TÜIK, 2013. Bitkisel Üretim İstatistikleri. http://www.tuik.gov.tr/PreTablo.do?alt_id=1001 (Erişim tarihi: 27.02.2015).

Yurdakul, F. 1998. Pamuk Üretimi ile Pamuk Fiyatı Arasındaki İlişkinin Ekonometrik Analizi: KoyckAlmon Yaklaşımı. Çukurova Üniversitesi İktisadi ve İdari Bilimler Fakültesi Dergisi, 8(1): 341-353. 